University of Nebraska - Lincoln

DigitalCommons@University of Nebraska - Lincoln

April 1991

\title{
Magneto-optic and optical characterization of Tb/Co compositionally modulated amorphous films
}

\author{
Liang-Yao Chen \\ University of Nebraska - Lincoln \\ Ping $\mathrm{He}$ \\ University of Nebraska - Lincoln \\ S. Nafis \\ University of Nebraska - Lincoln \\ William A. McGahan \\ University of Nebraska - Lincoln \\ John A. Woollam \\ University of Nebraska-Lincoln, jwoollam1@unl.edu \\ See next page for additional authors
}

Follow this and additional works at: https://digitalcommons.unl.edu/physicssellmyer

Part of the Physics Commons

Chen, Liang-Yao; He, Ping; Nafis, S.; McGahan, William A.; Woollam, John A.; and Sellmyer, David J., "Magneto-optic and optical characterization of Tb/Co compositionally modulated amorphous films" (1991). David Sellmyer Publications. 119.

https://digitalcommons.unl.edu/physicssellmyer/119

This Article is brought to you for free and open access by the Research Papers in Physics and Astronomy at DigitalCommons@University of Nebraska - Lincoln. It has been accepted for inclusion in David Sellmyer Publications by an authorized administrator of DigitalCommons@University of Nebraska - Lincoln. 


\section{Authors}

Liang-Yao Chen, Ping He, S. Nafis, William A. McGahan, John A. Woollam, and David J. Sellmyer 


\title{
Magneto-optic and optical characterization of $\mathrm{Tb} / \mathrm{Co}$ compositionally modulated amorphous films
}

\author{
Liang-Yao Chen, Ping He, Suraiya Nafis, William A. McGahan, John A. Woollam, \\ and D. J. Sellmyer \\ Departments of Electrical Engineering and Physics, University of Nebraska-Lincoln, Lincoln, \\ Nebraska 08588-0511 \\ Amorphous $\mathrm{Tb} / \mathrm{Co}$ compositionally modulated films were deposited on $\mathrm{Si}$ substrates with \\ different modulation layer thicknesses ranging from about 2.5 to $15 \AA$. The nominal \\ $\mathrm{Tb}$ to $\mathrm{Co}$ layer thickness ratios were systematically varied and the complex refractive index \\ ( $n$ and $k$ ) and polar magneto-optical Kerr effects (rotation and ellipticity) were measured \\ in the $3000-8000-\AA$ spectral range as well. The samples were divided into two groups. \\ In one group, the thickness of the Co layers was fixed, the Tb layer thickness varied. In the \\ second group, the thickness of the $\mathrm{Tb}$ layer was fixed, and that of the Co layer thickness \\ varied. The Kerr rotation and the coercivities of the samples showed very consistent and \\ interesting changes. X-ray diffraction and $\mathrm{x}$-ray fluorescence were also performed on the \\ samples, which revealed layered structures, or compositional modulation, and provided \\ information on the $\mathrm{Tb}$ to $\mathrm{Co}$ atomic ratios in the samples.
}

\section{INTRODUCTION}

Amorphous rare-earth-transition-metal (RE-TM) magnetic alloys are being considered for erasable magnetooptical (MO) recording, although, recently, metal multilayers such as $\mathrm{Co} / \mathrm{Pt}$ are studied as new candidates. ${ }^{1}$.MO properties of RE-TM alloys are strongly dependent on the composition, thus the RE content can be adjusted to tune the recording performance. Although many studies have been made in the last decade, ${ }^{2-6}$ the role of the localized $\mathrm{RE}$ moments played in the RE-TM(Fe, Co) alloys still remains controversial. Intrinsically, the magneto-optical Kcrr effect (MOKE) is primarily from the "magnetic". electrons, i.e., $d$ and $f$ electrons for the RE-TM alloys since the MOKE is proportional to the spin-orbit coupling strength. Therefore, a spectroscopic MOKE is useful to probe the role of the RE elements in the alloys. In this paper, we present optical and polar Kerr experimental re-. sults for compositionally modulated magnetic $\mathrm{Tb} / \mathrm{Co}$ films with varied $\mathrm{Tb}$ to Co concentration ratios, and discuss some interesting new results.

\section{EXPERIMENTAL METHODS}

A rotating analyzer magneto-optical spectrometer was used to measure the polar Kerr effect (both the Kerr ro-

TABLE I. Sample bilayer structures.

\begin{tabular}{ll}
\hline \hline Sample group I & \\
\hline $\mathrm{Tb}(2.5) / \mathrm{Co}(10)$ & Sample group II \\
$\mathrm{Tb}(5) / \mathrm{Co}(10)$ & $\mathrm{Tb}(10) / \mathrm{Co}(2.5)$ \\
$\mathrm{Tb}(7.5) / \mathrm{Co}(10)$ & $\mathrm{Tb}(10) / \mathrm{Co}(5)$ \\
$\mathrm{Tb}(10) / \mathrm{Co}(10)$ & $\mathrm{Tb}(10) / \mathrm{Co}(7.5)$ \\
$\mathrm{Tb}(12.5) / \mathrm{Co}(10)$ & $\mathrm{Tb}(10) / \mathrm{Co}(10)$ \\
$\mathrm{Tb}(15) / \mathrm{Co}(10) \quad$ Extra sample $\mathrm{Tb}(8.75) / \mathrm{Co}(10)$ & $\mathrm{Tb}(10) / \mathrm{Co}(12.5)$ \\
&
\end{tabular}

Angstrom units. tation $\theta_{k}$ and Kerr ellipticity $\epsilon_{k}$ ), in the 3000-8000- $\AA$ spectral range. This technique has been discussed in detail in Ref. 7. Ellipsometric measurements were also made on a variable angle spectroscopic ellipsometer ${ }^{8}$ in the same spectrum (3000-8000 $\AA$ ) and at incident angles of $60^{\circ}-70^{\circ}$ to obtain the optical constants $n$ and $k$. The samples used for this experiment consisted of Si substrates onto which compositionally modulated $\mathrm{Tb} / \mathrm{Co}$ magnetic films were magnetron sputtered. During sputtering, the substrate was kept at $19 .^{\circ} \mathrm{C}$ to obtain amorphous layers, as verified by $\mathrm{x}$-ray diffraction. The nominal $\mathrm{Co}$ and $\mathrm{Tb}$ layer thicknesses varied systematically from 2.5 to $15 \AA$ as shown in Table I. For all samples, the total thicknesses of magnetic films were made optically thick $(1000 \AA)$ to avoid optical interference effects, and both the MOKE and ellipsometric measurements were made at room temperature.

\section{RESÜLTS AND DISCUSSION}

The complex index of refraction $\tilde{n}=n+i k$ and magneto-optical Kerr rotation $\theta_{k}$ and ellipticity $\epsilon_{k}$ for

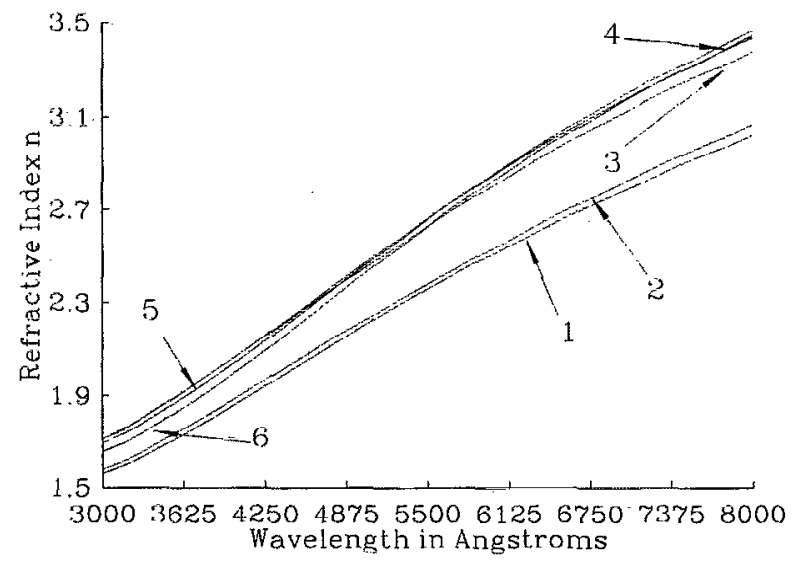

FIG. 1. Index of refraction $n$ of the $\mathrm{Tb} / \mathrm{Co}$ multilayer system. 1: $\mathrm{Tb}(10) /$ $\mathrm{Co}(2.5) ; 2: \mathrm{Tb}(10) / \mathrm{Co}(5) ; 3: \mathrm{Tb}(10) / \operatorname{Co}(7.5) ; 4: \mathrm{Tb}(10) / \mathrm{Co}(10) ; 5:$ $\mathrm{Tb}(10) / \mathrm{Co}(12.5) ; 6: \mathrm{Tb}(10) / \mathrm{Co}(15)$. 


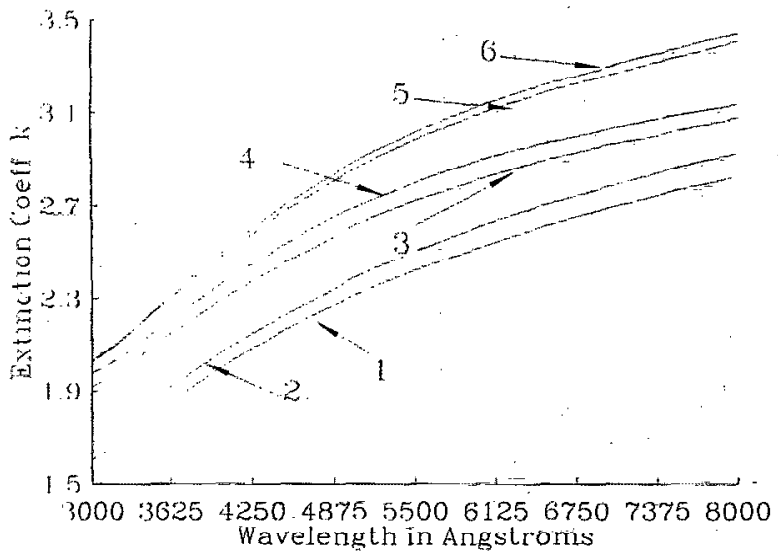

FIG. 2. Extinction coefficient $k$ of the $\mathrm{Tb} / \mathrm{Co}$ multilayer system. 1: $\mathrm{Tb}(10) / \mathrm{Co}(2.5) ; 2: \mathrm{Tb}(10) / \mathrm{Co}(5) ; 3: \mathrm{Tb}(10) / \mathrm{Co}(7.5) ; 4: \mathrm{Tb}(10) /$ $\mathrm{Co}(10) ; 5: \mathrm{Tb}(10) / \mathrm{Co}(12.5) ; 6: \mathrm{Tb}(10) / \mathrm{Co}(15)$.

group-II samples with the indicated nominal $\mathrm{Tb}$ and $\mathrm{Co}$ layer thicknesses are shown in Figs. 1-4. In addition, the complex magneto-optical parameter $\widetilde{Q}=Q_{1}+i Q_{2}$ was also calculatcd from experimental data based on classical electrodynamic theory, but is not shown. The results of group-I samples which are not shown in this paper are similar to those of group-II samples.

The optical constants $n$ and $k$ in Figs. 1 and 2 show the effect of the $\mathrm{Tb}$ to Co composition changes in the samples. There is a sudden increase in refractive index $n$ when the Co layers reach $7.5 \AA$. This is likely due to the change from alloy behavior to compositionally modulated behavior. That is, distinguishable layers are formed at this thickness. This point has been confirmed using by $\mathrm{x}$-ray diffraction which showed a "superlattice" peak for samples with Co thicknesses greater than $7.5 \AA$, but no peak at all for thicknesses less than this. The extinction coefficient $k$ increases with Co composition increase, approaching the value of

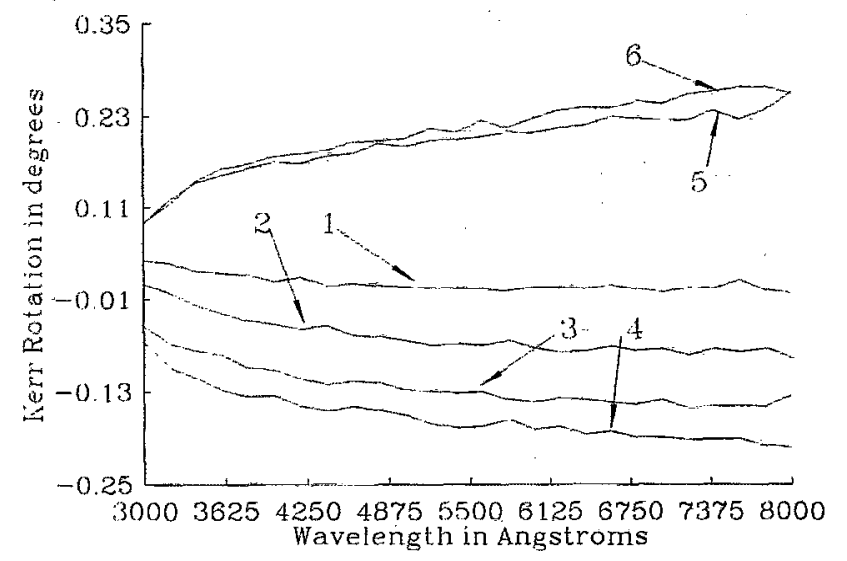

FIG. 3. Magneto-optical Kerr rotation of the $\mathrm{Tb} / \mathrm{Co}$ multilayer system. 1: $\mathrm{Tb}(10) / \mathrm{Co}(2.5) ; 2: \mathrm{Tb}(10) / \mathrm{Co}(5) ; 3: \mathrm{Tb}(10) / \mathrm{Co}(7.5) ; 4: \mathrm{Tb}(10) /$ $\mathrm{Co}(10) ; 5: \mathrm{Tb}(10) / \mathrm{Co}(12.5) ; 6: \mathrm{Tb}(10) / \mathrm{Co}(15)$.

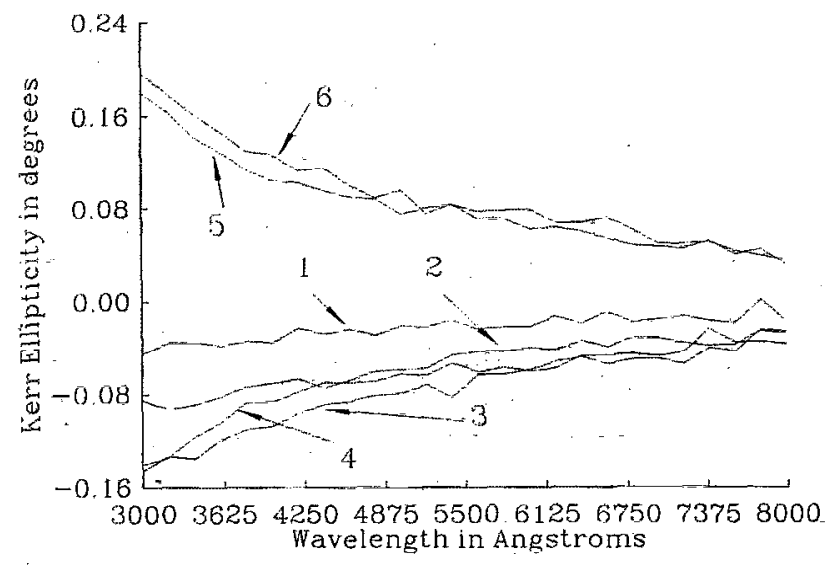

FIG. 4. Magneto-optical Kerr ellipticity of the $\mathrm{Tb} / \mathrm{Co}$ multilayer system. 1: $\mathrm{Tb}(10) / \mathrm{Co}(2.5) ; 2: \mathrm{Tb}(10) / \mathrm{Co}(5) ; 3: \mathrm{Tb}(10) / \mathrm{Co}(7.5) ; 4: \mathrm{Tb}(10) /$ $\mathrm{Co}(10) ; 5: \mathrm{Tb}(10) / \mathrm{Co}(12.5) ; 6: \mathrm{Tb}(10) / \mathrm{Co}(15)$.

bulk Co. Thus there is a systematic change of optical constants with Co concentration.

Figures 3-5 show the Kerr rotation $\theta_{k}$, Kerr ellipticity $\epsilon_{k}$, and Kerr rotation loops. Several interesting effects are observed. First of all, additional Co added to the system causes systematic changes of $\theta_{k}$ and $\epsilon_{k}$ over the entire spectral range, particularly for $\epsilon_{k}$ in the short-wavelength range. Sign changes in $\theta_{k}$ and $\epsilon_{k}$ can be seen clearly. Also, Figs. 5(b), 5(c), and 5(d) show the Kerr rotation loops exhibiting perpendicular anisotropy when the $\mathrm{Tb}$ to $\mathrm{Co}$ thickness ratio is about 8:10. An extra sample, $\mathrm{Tb}(8.75) /$ $\mathrm{Co}(10)$, was made to check the magnetic properties' of samples near the "critical point" where the magnetization of the films changed sign. The Kerr rotation loop of the extra sample with 8 kOe coercivity is shown in Fig. 5(c). The increase of coercivity from both the positive and negative sides of the magnetization near the $\mathrm{Tb}$-Co layer thickness ratio of 8:10 implies that there exists a magnetic compensation point, although magnetization measurements
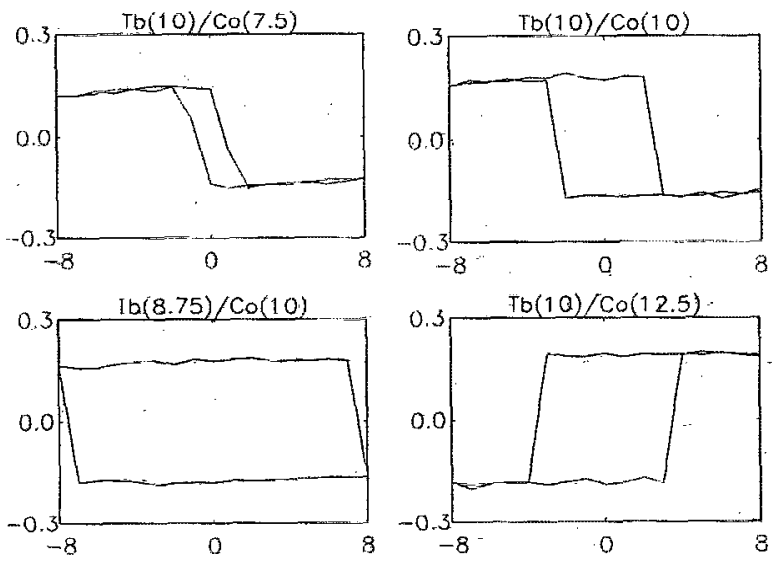

FIG. 5. Magneto-optical Kerr rotation loops of the $\mathrm{Tb} / \mathrm{Co}$ multilayer system. The $x$ axes are the magnetic field in $k G$, and the $y$ axes are Kerr rotations (at $\lambda=5000 \AA$ ) in degrees. 
need to be made to confirm this point. On the other hand, for the $\mathrm{Tb}$-rich sample, $\mathrm{Tb}(10) / \mathrm{Co}(2.5)$, the Kerr effects were very small, and a perpendicular anisotropy was not present (the Kerr rotation loop for this sample is not shown). This result agrees with Buschow's report that amorphous $\mathrm{Tb}_{x} \mathrm{Co}_{1-x}$ alloys with $x>0.4$ have a Curie temperature below room temperature. For Co-rich samples, such as $\mathrm{Tb}(2.5) / \mathrm{Co}(10)$, the Kerr effects were not small, but the samples have no perpendicular magnetic anisotropy. There are still many questions about the roles. played by $\mathrm{Tb}$ and $\mathrm{Co}$ in either compositionally modulated films or alloys. More experimental work, such as photoemission to explore in detail the electronic states near the Fermi level, as well as theoretical studies in this system, is needed.

\section{ACKNOWLEDGMENT}

This research was supported by the National Science Foundation (NSF) Grant No. DMR 8605367.

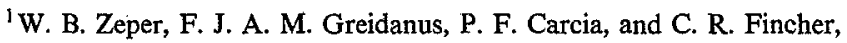
J. Appl. Phys. 65, 4971 (1989).

${ }^{2}$ P. Chaudhari, J. J. Cuomo, and R. J. Gambino, Appl. Phys. Lett. 22, 337 (1973)

${ }^{3}$ M. Hartmann, J. Braat, and B. Jacobs, IEEE Trans. Magn. MAG-20, 1013 (1984).

${ }^{4}$ T. R. McGuire and M. Hartmann, IEEE Trans Magn. MAG-22, 1224 (1986).

${ }^{5}$ K. H. J. Buschow, J. Appl. Phys. 51, 2795 (1980).

${ }^{6}$ G. A. N. Connell, J. Magn. Magn. Mater. 54-57, 1561 (1986).

${ }^{7}$ L. Y. Chen and J. A. Woollam, SPIE 1166, 267 (1989)

${ }^{8}$ J. A. Woollam, P. G. Snyder, and M. C. Rost, Thin Solid Films 166, 317 (1988). 